COMMISSION OF INQUIRY (1989) Occupational Therapy: an Emerging Profession in Health Care. London: Duckworth.

DEPARTMENT OF EMPLOYMENT AND DEPARTMENT OF EDUCATION AND SCIENCE (1986) Working TogetherEducation and Training. London: HMSO.

Department of Health (1989) Working for PatientsWorking Paper 10: Education and Training. London: HMSO.
Finlay, L. Occupational Therapy Practice in Psychiatry. London: Chapman Hall.

JARMAN, B. (1983) Identification of underprivileged areas. British Medical Journal, 286, 1705-1709.

TEST, M. A. (1989) The training and community living model: delivering treatment and rehabilitation services through a continuous treatment team. In Rehabilitation of the Seriously Mentally IIl (ed. Liberman, R. P.). New York: Plenum.

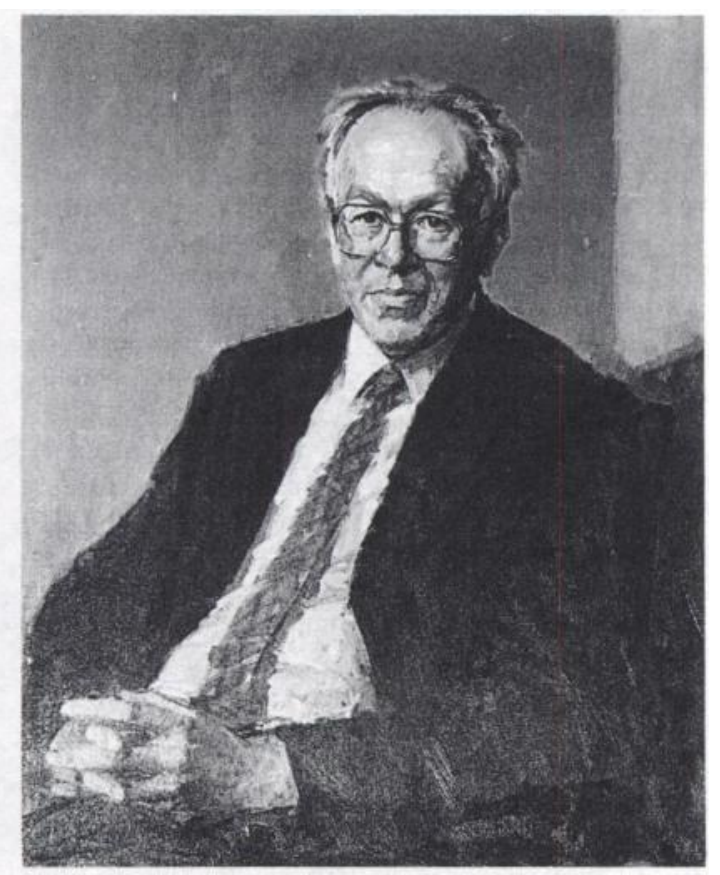

This portrait of Dr Jim Birley, President of the Royal College of Psychiatrists from 1987-1990, now hangs in the Council Room of the College with portraits of other past Presidents. The Officers are grateful to those Members who contributed to the Portrait Fund.

\title{
Cumulated Index Medicus
}

Now that the Library has Medline on CD Rom, it is no longer necessary to hold the hard copies of Cumulated Index Medicus. At its last meeting, the Library Committee agreed that these volumes, which cover the period 1981 to 1989 , should be offered to other libraries.

Anyone interested in having them should contact the Librarian. The books occupy some six metres of shelf space. 